\title{
Oral steroid prophylaxis is effective in preventing esophageal strictures after large endoscopic resection
}

\author{
Jean-Philippe Ratone ${ }^{a}$, Erwan Bories ${ }^{a}$, Fabrice Caillola, Christian Pesenti ${ }^{a}$, Sebastien Godat ${ }^{a}$, \\ Flora Poizat ${ }^{\mathrm{b}}$, Chiara De Cassan ${ }^{\mathrm{a}}$, Marc Giovannini ${ }^{\mathrm{a}}$
}

Paoli-Calmettes Institute, Marseille, France

\section{Abstract}

\section{Introduction}

In recent decades, the management of superficial esophageal lesions has evolved significantly with the addition

${ }^{a}$ Endoscopy Unit (Jean-Philippe Ratone, Erwan Bories, Fabrice Caillol, Christian Pesenti, Sebastien Godat, Chiara De Cassan, Marc Giovannini); 'Pathology Unit (Flora Poizat), Paoli-Calmettes Institute, Marseille, France

Conflict of Interest: None

Correspondence to: Dr Jean-Philippe Ratone, Endoscopy Unit, 232 Boulevard de Sainte Marguerite, 13009 Marseille, France, Tel.: +33 491223568, e-mail: jpratone@hotmail.fr

Received 16 May 2016; accepted 05 July 2016; published online 6 September 2016

DOI: http://dx.doi.org/10.20524/aog.2016.0085 of therapeutic endoscopy, i.e., endoscopic mucosal resection (EMR) and endoscopic submucosal dissection (ESD). EMR for Barrett's esophagus with high-grade dysplasia (HGD) and intramucosal adenocarcinoma (IMC) is performed by multiband or cap mucosectomy, with a success rate of up to $87 \%$ for neoplasia [1-4]. Furthermore, after complete endoscopic resection of Barrett's esophagus with HGD or IMC, the incidence of metachronous neoplasia appears to decrease [5-7]. Complete Barrett's eradication can be performed by endoscopic resection or radiofrequency ablation, but its effectiveness is limited because of the high risk of iatrogenic stricture, which ranges between $17 \%$ and $88 \%[4,5,8,9]$. Treatment of these stenosis requires multiple sessions of dilation, impairing the patient's quality of life.

Previous studies have shown that either local [10-12] or systemic corticosteroids [13-15] can effectively reduce the need for endoscopic balloon dilation after large ESD. We report 
our experience from using prophylaxis with oral steroids to prevent iatrogenic stenosis after endoscopic resection of Barrett's esophagus extending to at least half the circumference. The primary aim of our retrospective study was to determine the rate of stricture under oral steroid prophylaxis after large endoscopic resection. Our secondary aim was to determine the association of this preventive strategy with adverse effects and complications.

\section{Patients and methods}

\section{Patients}

We retrospectively included all patients who underwent large EMR for Barrett's esophagus between July 2013 and September 2015 and were treated preventively with oral corticosteroids. Large EMR was defined as resection of more than half of the esophageal mucosa circumference. Indications for EMR were confirmed IMC, HGD, or low-grade dysplasia (LGD) Barrett's esophagus. Patients were excluded if they received additional radiofrequency treatment, or if they had a known history of psychiatric illness, diabetes or osteoporosis. Oral informed consent to the EMR, steroid therapy, and dilation was obtained from all patients.

\section{Treatment protocol}

EMR was performed by 4 operators experienced in esophageal EMR and 2 operators with poor experience in esophageal EMR under their direct supervision. Barrett's esophagus was examined under high-definition white-light endoscopy (EG29-i10, EG-2990Zi, PENTAX MEDICAL@), Tokyo, JAPAN) and, if necessary, by chromoendoscopy with acetic acid. All resections were performed using a multiband mucosectomy technique (Duette; Cook Medical, WinstonSalem NC). If necessary, a submucosal injection of saline mixed with indigo carmine was performed. A microprocessorcontrolled electrosurgical generator (ERBE VIO 300; ERBE, Tübingen, Germany) was used. Resection was performed from the palisade vessels of the gastroesophageal junction distally and was extended to remove at least a hemi-circumference of Barrett's esophagus (Fig. 1). The Prague classification for Barrett's esophagus [16] was used in all patients and the Paris classification [17] was used for nodular or suspicious lesions. Lesions classified 0-IIc and 0-III by the Paris classification were considered ineligible for EMR. For simplicity, we used the codes R0 for healthy vertical margins and R1 for positive vertical margins (lateral margins could not be evaluated given the large piecemeal EMR).

Oral prednisolone was started 1 day after EMR in a dosage of $30 \mathrm{mg} /$ day. The dose was then gradually tapered in decrements of $5 \mathrm{mg}$ /day every 2 weeks for 1 month, followed by decrements of $5 \mathrm{mg}$ /day every week for the next 4 weeks.

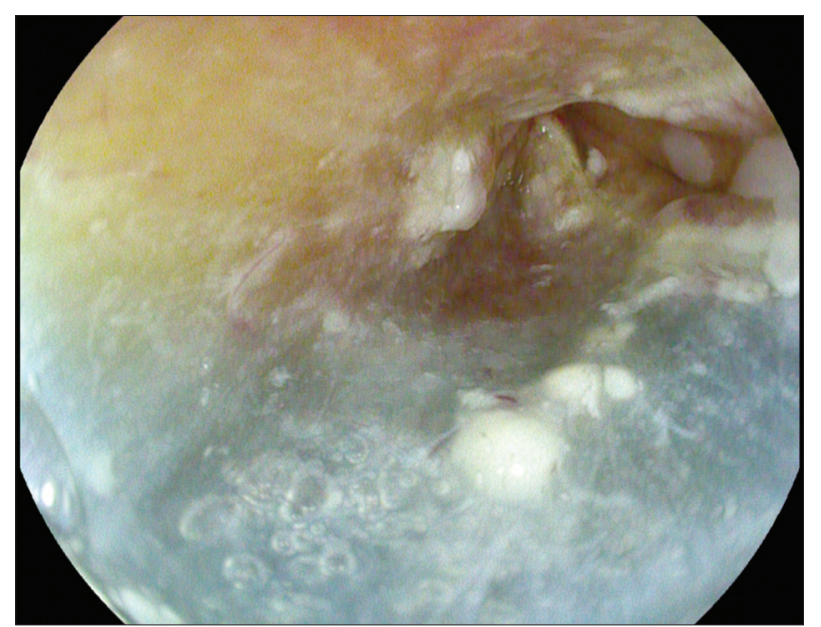

Figure 1 Example of large esophageal endoscopic mucosal resection

\section{Follow up}

Gastroscopy was scheduled at 2, 6, 12, and 24 months after EMR, with biopsies if necessary, and a new EMR session if the initial treatment was incomplete. Any symptomatic esophageal stricture was managed by hydrostatic endoscopic dilations (Hercule; Cook Medical $12 \mathrm{~mm} / 15 \mathrm{~mm} / 18 \mathrm{~mm}$, WinstonSalem, NC). Dilation was performed up to a maximum of $18 \mathrm{~mm}$ or until a laceration or tear was seen on direct visualization.

\section{Statistical analysis}

Patient demographics and Barrett's esophagus characteristics were retrieved from a computer database. All data were analyzed retrospectively.

\section{Results}

Between July 2013 and September 2015, 31 patients (27 men, 4 women, sex ratio 7:1; mean age 63 years) with biopsy-proven Barrett's LGD, HGD or IMC met the inclusion criteria. Patients' characteristics and resection details are shown in Table 1.

The median circumferential extent and maximum Barrett's mucosa length were respectively $3 \mathrm{~cm}$ (range C0-C10) and $5 \mathrm{~cm}$ (range M2-M11). Pre-EMR histology showed 19 patients with IMC, 8 with HGD and 4 with LGD. Based on the EMR specimen, definitive histology was LGD in 13 patients, IMC in 16 and submucosal carcinoma in $2(\mathrm{sm} 1=1, \mathrm{sm} 2=1)$. The resection was complete (R0) in 28 patients, requiring 1-3 sessions (median 2). Both patients with submucosal cancer had positive vertical margins (R1). They underwent surgery and definitive histology was pT1bN0M0.

Oral prednisolone in a dosage of $30 \mathrm{mg} /$ day was started the day after EMR, once the patients were permitted oral 
Table 1 Patient demographics and clinical outcome features

\begin{tabular}{|c|c|c|c|c|c|c|c|c|c|}
\hline Patient & Age, y & Sex & $\begin{array}{l}\text { Prague } \\
\text { classification }\end{array}$ & $\begin{array}{l}\text { Pre-EMR } \\
\text { biopsies }\end{array}$ & $\begin{array}{l}\text { Staging } \\
\text { EMR }\end{array}$ & $\begin{array}{l}\text { Total of } \\
\text { EMR } \\
\text { sessions }\end{array}$ & $\begin{array}{l}\text { Profound } \\
\text { margins } \\
(\mathrm{R} 0 \text { or } \mathrm{R} 1)\end{array}$ & $\begin{array}{l}\text { Resection greater } \\
\text { than } 75 \% \text { in } 2 \text { or } 3 \\
\text { sessions: (yes or no) }\end{array}$ & $\begin{array}{l}\text { Median } \\
\text { follow up } \\
\text { (months) }\end{array}$ \\
\hline 1 & 55 & M & C2M5 & HGD & LGD & 3 & R0 & Yes & 11 \\
\hline 2 & 69 & M & C3M5 & IMC & IMC & 2 & R0 & Yes & 12 \\
\hline 3 & 62 & M & C3M7 & IMC & IMC & 3 & R0 & Yes & 22 \\
\hline 4 & 68 & M & C5M7 & IMC & IMC & 2 & R0 & Yes & 10 \\
\hline 5 & 61 & M & $\mathrm{C} 2 \mathrm{M} 4$ & IMC & IMC & 2 & R0 & Yes & 10 \\
\hline 6 & 64 & M & C1M2 & IMC & IMC & 2 & R0 & Yes & 10 \\
\hline 7 & 72 & M & C3M7 & HGD & LGD & 2 & R0 & Yes & 6 \\
\hline 8 & 55 & M & $\mathrm{C} 1 \mathrm{M} 2$ & HGD & LGD & 2 & R0 & Yes & 2 \\
\hline 9 & 53 & M & C2M3 & IMC & IMC & 2 & R0 & Yes & 10 \\
\hline 10 & 72 & M & $\mathrm{C} 2 \mathrm{M} 4$ & HGD & LGD & 2 & R0 & Yes & 15 \\
\hline 11 & 60 & F & C0M2 & IMC & IMC & 1 & R0 & No & 15 \\
\hline 12 & 65 & M & C5M7 & HGD & LGD & 3 & R0 & Yes & 16 \\
\hline 13 & 60 & M & C3M5 & IMC & IMC & 2 & R0 & Yes & 16 \\
\hline 14 & 79 & $\mathrm{M}$ & C5M7 & HGD & LGD & 2 & R0 & Yes & 23 \\
\hline 15 & 68 & M & C5M5 & IMC & IMC & 2 & R0 & Yes & 22 \\
\hline 16 & 72 & $\mathrm{M}$ & C5M7 & IMC & IMC & 2 & R0 & Yes & 23 \\
\hline 17 & 50 & M & C2M5 & HGD & LGD & 2 & R0 & Yes & 21 \\
\hline 18 & 43 & F & $\mathrm{C} 1 \mathrm{M} 2$ & LGD & LGD & 2 & R0 & Yes & 23 \\
\hline 19 & 69 & M & C5M5 & IMC & IMC & 2 & R0 & Yes & 20 \\
\hline 20 & 57 & M & C3M4 & LGD & LGD & 2 & R0 & Yes & 18 \\
\hline 21 & 71 & M & C8M8 & IMC & IMC & 3 & R0 & Yes & 7 \\
\hline 22 & 57 & M & C5M6 & IMC & IMC & 2 & R0 & Yes & 1 \\
\hline 23 & 83 & $\mathrm{M}$ & C6M8 & IMC & IMC & 2 & R0 & Yes & 8 \\
\hline 24 & 58 & M & C2M6 & LGD & LGD & 2 & R0 & Yes & 8 \\
\hline 25 & 64 & M & C10M11 & IMC & Sm1 & 1 & $\mathrm{R} 1$ & No & 2 \\
\hline 26 & 71 & M & C5M5 & IMC & IMC & 2 & R0 & Yes & 8 \\
\hline 27 & 67 & $\mathrm{~F}$ & C1M3 & LGD & LGD & 1 & R0 & No & 7 \\
\hline 28 & 63 & M & C1M3 & HGD & LGD & 1 & R0 & No & 6 \\
\hline 29 & 72 & M & $\mathrm{C} 2 \mathrm{M} 4$ & IMC & IMC & 1 & R0 & No & 12 \\
\hline 30 & 69 & M & C3M5 & IMC & $\operatorname{Sm} 2$ & 1 & $\mathrm{R} 1$ & No & 4 \\
\hline 31 & 72 & $\mathrm{~F}$ & C2M3 & IMC & IMC & 1 & R0 & No & 1 \\
\hline
\end{tabular}

LGD, low-grade dysplasia; HGD, high-grade dysplasia; IMC, intramucosal adenocarcinoma; sm, submucosal infiltration; EMR, endoscopic mucosal resection

intake. All patients included in this study followed the steroid protocol.

Immediate and secondary adverse events were recorded during a median follow up of 10 months (range 1-22). No digestive perforation occurred in any case. Two patients had significant bleeding requiring endoscopic hemostasis. One patient died from a sudden and massive hemorrhage $48 \mathrm{~h}$ after the second EMR session.

Four patients (13\%) required endoscopic balloon dilation for symptomatic esophageal stricture. The endoscopic dilation was effective in all cases, requiring 1-4 sessions (median 2).
The mean dilation diameter was $16.5 \mathrm{~mm}$ [15 mm-18 mm]. There were no adverse events related to oral steroids. The study design is shown in Fig. 2.

\section{Discussion}

Endoscopic resection has recently been accepted as firstline therapy for early esophageal cancers, such as squamous cell carcinoma and dysplasia of Barrett's esophagus. Secondary 


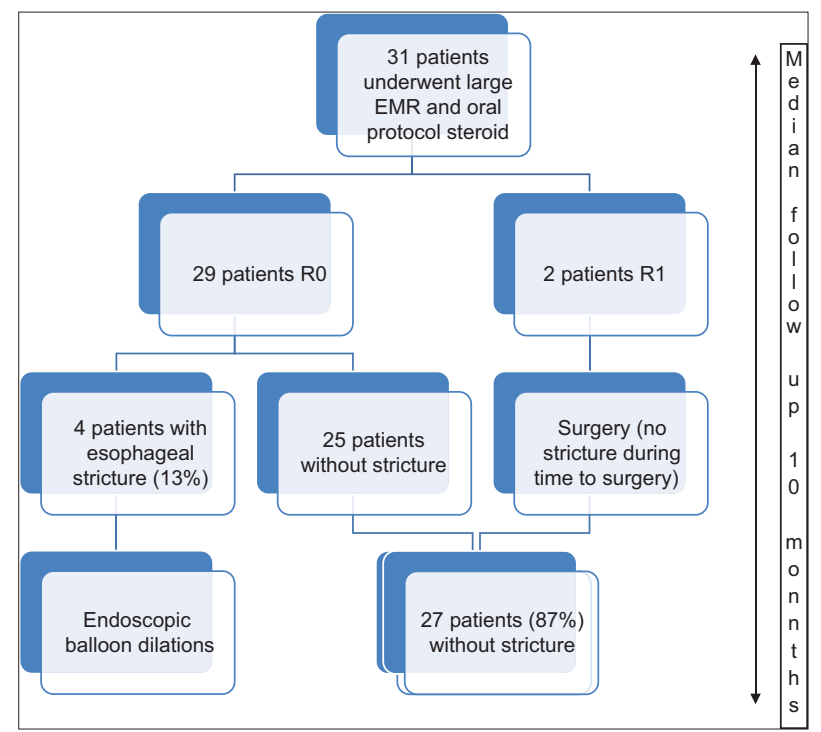

Figure 2 Study design

RO, healthy vertical margins; R1, positive vertical margins; $E M R$, endoscopic mucosal resection

esophageal stricture is a common and well known complication after a large resection. It necessitates some iterative endoscopic procedures and hospitalizations, and may delay or compromise treatment if more sessions are needed. Prophylactic selfexpandable metal stent insertion has been proposed, but the morbidity rate is excessive [18]. Anti-inflammatory approaches for preventing esophageal strictures after endoscopic resection are based on the concept that subsequent strictures may be suppressed by inhibiting the infiltration of inflammatory cells, the hyperplasia of granulation, and fibrosis. Local injection of triamcinolone seems to be effective, but is of limited use in large circumferential resections [10,11]. Furthermore, it may cause an ulcer at the injection site.

Several research teams have studied preventive systemic corticosteroid therapy and have reported promising early results [13-15]. However, high doses of prednisolone have been associated with adverse effects, such as severe infections, peptic ulcers, hyperglycemia, psychiatric symptoms, and osteoporosis [19].

Since the publication of the above results, we have been using a low dose of systemic corticosteroids to reduce the stricture rate post EMR. This study presents the results from clinical practice in our center. This retrospective study provides more support for the use of systemic corticosteroids in this context. Indeed, the stricture rate $(13 \%)$ was much lower than the $17-88 \%$ reported in the literature $[4,5,8,9]$. We use relatively low doses over a limited period and it seems unlikely that this has an impact in the long term. Moreover, the stricture rate increases drastically when $75 \%$ of the circumference is involved [20] and in our study 24/31 patients underwent circumferential resection in 2 to 3 sessions (Table 1 ). The other patients (7/31) underwent resection in 1 session of esophageal mucosa larger than the half-circumference, but less than $75 \%$ of the esophageal lumen (Table 1).

There were 3 early (within $48 \mathrm{~h}$ ) adverse events (3 hemorrhages and no perforation). Two hemorrhages were treated endoscopically. One patient had a sudden fatal hemorrhagic shock $48 \mathrm{~h}$ after the second EMR session. None of the complications were related to steroid therapy. The two patients with submucosal infiltration underwent laparoscopic transhiatal esophago-gastrectomy.

Our study is, of course, limited by being a retrospective analysis and by the relatively small number of patients. Indeed, only 31 patients were able to benefit from the steroid therapy protocol in its entirety. Some patients refused and the institution of the protocol was at the discretion of the operator. Although the treatment duration was short (8 weeks), patients with a psychiatric history, known diabetes or osteoporosis were not treated. Furthermore, we excluded from this analysis patients who underwent radiofrequency ablation after EMR, so as not to add a confounding factor.

The findings of our study are consistent with those reported in the literature, and the side effects appear to be mild, although this will need to be verified by an intention-to-treat study.

In conclusion, esophageal strictures cause dysphagia, which obliges the patient to undergo repeated balloon dilation procedures or implantation of temporary stents. These esophageal strictures decrease the patient's quality of life and have their own potential complications (perforation, failure). Anti-inflammatory approaches are promising and have been shown to be effective in several studies. However, a multicenter randomized study will be needed to determine the best route of administration and other related factors (local or oral and posology). We believe that several surgical resections related to this complication could be avoided. With developments in the ESD technique the stricture rate may increase [21]. In the future, a tissue-engineering approach could be another line of research, along with cell therapies [22,23]. New biological agents are also promising [24].

\section{Summary Box}

\section{What is already known:}

- Secondary esophageal stricture after large resection is a common and well known complication

- Oral or local steroids have shown very promising results in several research teams

- The development of new endoscopic resection techniques, such as endoscopic submucosal resection (EMR), will increase the iatrogenic stricture rate

\section{What the new findings are:}

- This study confirms the potential value of oral steroid therapy in large EMR

- This therapy appears to be safe in low doses, without frequent adverse effects

- Oral steroid therapy should be considered for any resection involving more than $50 \%$ of the circumference 


\section{References}

1. Pech O, Behrens A, May A, et al. Long-term results and risk factor analysis for recurrence after curative endoscopic therapy in 349 patients with high-grade intraepithelial neoplasia and mucosal adenocarcinoma in Barrett's oesophagus. Gut 2008;57:1200-1206.

2. Saligram S, Chennat J, Hu H, Davison JM, Fasanella KE, McGrath K. Endotherapy for superficial adenocarcinoma of the esophagus: an American experience. Gastrointest Endosc 2013;77:872-876.

3. Pouw RE, Seewald S, Gondrie JJ, et al. Stepwise radical endoscopic resection for eradication of Barrett's oesophagus with early neoplasia in a cohort of 169 patients. Gut 2010;59:1169-1177.

4. Lopes CV, Hela M, Pesenti C, et al. Circumferential endoscopic resection of Barrett's esophagus with high-grade dysplasia or early adenocarcinoma. Surg Endosc 2007;21:820-824.

5. Chennat J, Konda VJ, Ross AS, et al. Complete Barrett's eradication endoscopic mucosal resection: an effective treatment modality for high-grade dysplasia and intramucosal carcinoma-an American single-center experience. Am J Gastroenterol 2009;104:2684-2692.

6. Wani S, Puli SR, Shaheen NJ, et al. Esophageal adenocarcinoma in Barrett's esophagus after endoscopic ablative therapy: a meta-analysis and systematic review. Am J Gastroenterol 2009;104:502-513.

7. Phoa KN, van Vilsteren FG, Weusten BL, et al. Radiofrequency ablation vs endoscopic surveillance for patients with Barrett esophagus and low-grade dysplasia: a randomized clinical trial. JAMA 2014;311:1209-1217.

8. van Vilsteren FG, Pouw RE, Seewald S, et al. Stepwise radical endoscopic resection versus radiofrequency ablation for Barrett's oesophagus with high-grade dysplasia or early cancer: a multicentre randomised trial. Gut 2011;60:765-773.

9. Seewald S, Akaraviputh T, Seitz U, et al. Circumferential EMR and complete removal of Barrett's epithelium: a new approach to management of Barrett's esophagus containing high-grade intraepithelial neoplasia and intramucosal carcinoma. Gastrointest Endosc 2003;57:854-859.

10. Hanaoka N, Ishihara R, Takeuchi $\mathrm{Y}$, et al. Intralesional steroid injection to prevent stricture after endoscopic submucosal dissection for esophageal cancer: a controlled prospective study. Endoscopy 2012;44:1007-1011.

11. Hashimoto S, Kobayashi M, Takeuchi M, Sato Y, Narisawa R, Aoyagi Y. The efficacy of endoscopic triamcinolone injection for the prevention of esophageal stricture after endoscopic submucosal dissection. Gastrointest Endosc 2011;74:1389-1393.

12. Bahin FF, Jayanna M, Williams SJ, Lee EY, Bourke MJ. Efficacy of viscous budesonide slurry for prevention of esophageal stricture formation after complete endoscopic mucosal resection of shortsegment Barrett's neoplasia. Endoscopy 2016;48:71-74.

13. Yamaguchi $N$, Isomoto $H$, Nakayama $T$, et al. Usefulness of oral prednisolone in the treatment of esophageal stricture after endoscopic submucosal dissection for superficial esophageal squamous cell carcinoma. Gastrointest Endosc 2011;73:1115-1121.

14. Sato $\mathrm{H}$, Inoue $\mathrm{H}$, Kobayashi $\mathrm{Y}$, et al. Control of severe strictures after circumferential endoscopic submucosal dissection for esophageal carcinoma: oral steroid therapy with balloon dilation or balloon dilation alone. Gastrointest Endosc 2013;78:250-257.

15. Isomoto H, Yamaguchi N, Minami H, Nakao K. Management of complications associated with endoscopic submucosal dissection/ endoscopic mucosal resection for esophageal cancer. Dig Endosc 2013;25 Suppl 1:29-38.

16. Sharma P, Dent J, Armstrong D, et al. The development and validation of an endoscopic grading system for Barrett's esophagus: the Prague C \& M criteria. Gastroenterology 2006;131:1392-1399.

17. The Paris endoscopic classification of superficial neoplastic lesions: esophagus, stomach, and colon: November 30 to December 1 , 2002. Gastrointest Endosc 2003;58(6 Suppl):S3-S43.

18. Holt BA, Jayasekeran V, Williams SJ, et al. Early metal stent insertion fails to prevent stricturing after single-stage complete Barrett's excision for high-grade dysplasia and early cancer. Gastrointest Endosc 2015;81:857-864.

19. Huscher D, Thiele K, Gromnica-Ihle E et al. Dose-related patterns of glucocorticoid-induced side effects. Ann Rheum Dis. 2009 Jul;68(7):1119-24.

20. Hanaoka N, Ishihara R, Uedo N, et al. Refractory strictures despite steroid injection after esophageal endoscopic resection. Endosc Int Open 2016;4:E354-E359.

21. Chevaux JB, Piessevaux H, Jouret-Mourin A, Yeung R, Danse E, Deprez PH. Clinical outcome in patients treated with endoscopic submucosal dissection for superficial Barrett's neoplasia. Endoscopy 2015;47:103-112.

22. Takagi R, Yamato M, Murakami D, et al. Fabrication and validation of autologous human oral mucosal epithelial cell sheets to prevent stenosis after esophageal endoscopic submucosal dissection. Pathobiology 2011;78:311-319.

23. Ohki T, Yamato M, Ota M, et al. Prevention of esophageal stricture after endoscopic submucosal dissection using tissue-engineered cell sheets. Gastroenterology 2012;143:582-588.e1-e2.

24. Sakaguchi Y, Tsuji Y, Ono S, et al. Polyglycolic acid sheets with fibrin glue can prevent esophageal stricture after endoscopic submucosal dissection. Endoscopy 2015;47:336-340. 